\title{
The design of paperless examination system based on C/S pattern
}

\author{
Honglong Xie
}

\author{
Nanchang institute of science \& technology, China
}

Keywords: Paperless examination; C/S pattern; System module; Software design

\begin{abstract}
The article has designed a paperless examination system based on C/S pattern. The main task of the system includes the examination setting, system information, system management, examinee examination management and teacher marking management. The examination time of examination system is flexible, examinee can randomly select examination questions, can play a certain role in the containment for cheating phenomenon of Colleges and Universities.
\end{abstract}

Paperless examination is the popular view of computer examination, based on a kind of optimized question bank resources, by means of modern information technology, through randomly combine the test papers to generate paperless examination papers to carry out an examination, and timely generate the test scores, set examination application, examination papers generating, examination on computer, examination papers marking and results generating, etc. As a integrated, pluralistic and new examination pattern. The main tool used in the examination is not the traditional pens and papers, but all kinds of examination terminal which take computer as the representative, is a new type of examination pattern appeared with the development of modern computer and communication technology.

Our country's education examination is changing from the traditional way of the written examination to the paperless examination pattern. The national paperless examination system has been put into use including "the national computer rank examination" for ministry of education, "high-tech computer information examination", "driver simulation examination", "accounting qualification examination" for ministry of labor and social security and so on, in addition, there are various and functional paperless examination system organized by colleges and universities, associations, companies, etc. have been widely used in different fields of our country.

\section{Introduction}

\section{Project background.}

Along with the rapid development of computer technology and network technology, and with the increasing perfect function of campus network for colleges and universities, many colleges and universities set up the network information management platform based on campus network, provided the advanced management means for improving the level of teaching management. Paperless examination has been widely used with its advantages of efficient, fair, safe and reliable, gradually replaced some traditional examination based on the papers and pens. At present, on-line examination system based on network has become a powerful complement and development of modern ways of examination. Compared with traditional written examination, online examination not only reduced the cost of manpower and material resources in aspects of organizing examination, examination papers marking and result calculating, etc. But also broke through the limitation of time and space, not only saved the resources, but also improved the objectivity, impartiality and accuracy of scoring, greatly improved the efficiency of the examination work.

\section{Practical significance.}

The open paperless examination system is an extension of the traditional examination, it made full use of database technology, greatly simplified the process of traditional examination. The development of this system has two advantages: on the one hand, as long as prepared enough question bank, then can dynamically manage various examination information. On the other hand, the examination time is flexible, can take the exam at any time within the specified time period. In 
addition, the biggest advantage of the open paperless examination system is the speed of examination marking is fast, the system can be given the objective examination scores on the spot at the end of the examination, computer scoring of examination papers gives the largest a sense of fairness to the examinee.

\section{C/S (Client/Server) pattern}

C/S (Client/Server) pattern is also called the C/S structure, is a pattern gradually grow up in the late 1980S, is one of the software system architectures. The key of C/S structure is the distribution of functions, some functions are implemented on the front end machine (the client), other functions are implemented on the rear end machine (server). The distribution of function is to reduce various bottleneck problems of the computer system. C/S pattern simply speak is the application system based on enterprise internal network, compared with B/S (Browser/Server) pattern, the biggest advantage of application system for C/S pattern is that don't rely on enterprise external network environment, namely, whether the enterprise can get to the Internet, all do not affect the application. Server usually adopts high performance PC, workstations, or minicomputer, and adopts the large database system, such as ORACLE, SYBASE, InfORMix or SQL Server. The client need to install a dedicated client software. Although the traditional C/S architecture adopts the open pattern, but this is just the one level of openness for the system development, in particular application, both in Client side and Server side all need specific software support. Due to the failure to provide users with an truly expected open environment, the software of $\mathrm{C} / \mathrm{S}$ structure needs to according to different operating system to develop the software with different versions, combines with the upgrading of products is very fast, has been difficult to adapt to more than one hundred computer LAN users to use at the same time, the cost is high and efficiency is low.

\section{System design}

\section{System function.}

The open paperless examination system mainly realized the following aspects of functions: examination setting is responsible for the examination information and the examinee distribution. System information is responsible for maintaining the examination question bank, the examinee information, and teachers information. System management is responsible for managing the information of administrators, and provide the functions of re-logining and password maintenance. Examinee examination management is responsible for the examinee examination and scores query. Teachers marking management is responsible for teachers marking, scores query and scores statistics.

\section{System module.}

According to the result of requirement analysis, this system can be divided into five modules: examination setting, system information, system management, examinee examination management and teachers marking management.

Examination setting: mainly responsible for the examination information and the examinee distribution.

System information: mainly responsible for maintaining the examination question bank, the examinee information, and teachers information.

System management: responsible for managing the information of administrators, and provide the functions of re-logining and password maintenance.

Examinee examination management: mainly responsible for the examinee examination and scores query.

Teachers marking management: mainly responsible for teachers marking, scores query and scores statistics.

\section{Detailed design.}

According to the basic principle of software engineering, the basic task of the detailed design phase is to determine how to concretely achieve the system that required, that is to say, through the 
design work of this stage, should get an accurate description of the target system, thus can directly translate this description into a program written in a programming language in the system implementation phase. According to the requirements analysis and design of system in front, carried on the detailed design for the database structure and the system program flow, the specific contents as follows:

1. The design of examination setting module

This module includes three sub-modules: "examination information" module is responsible for setting the basic information of the examination, and proceed the operation of adding, modifying, deleting, etc. for the examination information. "Examinee distribution" module is responsible for distributing the examinee for each examination, to proceed the operation of the examination room distribution, query, etc. for the examinee who don't have the examination room distribution. "Examination list" module is responsible for querying and printing the examinee list of each examination.

2. The design of system information module

This module includes three sub-modules: "examination questions setting" module is responsible for setting and maintaining the examination question bank, examination questions can be divided into subjective questions and objective questions. "Examinee management" module is responsible for maintaining the basic information of the examinee. "Teachers management" module is responsible for managing teachers' information, to proceed the operation of adding, modifying and deleting.

3. The design of system management module

This module includes the following function modules: "administrators information" module is responsible for maintaining the basic information of the administrators, including ID, name, password, phone and email of administrators. "Re-login" module is responsible for providing the function of re-logining, when re-login, will check the users' type. "Password maintenance" module is responsible for maintaining the users' password.

4. The design of examinee examination management module

This module includes two sub-modules: "examinee examination" module is responsible for providing the function of examinee examination, examination questions including objective questions and subjective questions. "Examinee scores query" module is mainly used to provide the function of examination scores querying and printing for examinee.

The design of teacher marking management module

This module includes the following function modules: "teachers marking" module is used for teachers to change and mark the part of subjective questions for examination papers. "Scores query" module is responsible for providing the functions of querying, sorting and printing of examination scores for teachers according to the examination code. "Scores statistics" module is responsible for counting the scores distribution of each examination.

\section{Conclusion}

Early design, the first done the detailed demand analysis, analyzed the system flow and operation data flow and put forward the system overall design, after refined, put forward the detailed design of system, through studying the function modules of the system, and further refined each function sub-module, through clear thinking, then began to design the database, and then is the coding and testing. In the process of system development, also met some problems, but solved one by one with the help of the teachers or classmates. Through this graduation design, realized as a software developer, should have good psychological quality, encounter problems don't panic and mess, calm thinking, any problems there will be a solution.

Paperless examination in the 21st century is the development direction of future examination pattern, the traditional written examination generally includes registration, proposition, examination papers making, examination papers protecting, examination, marking, waiting scores and scores publishing, archive, etc. The organization process is complex and cumbersome, the period is long, the requirement of confidential work is too high and vulnerable to encounter the interference of 
human factors. The paperless examination is completely overcome the above shortcomings, compared with traditional written examination, paperless examination showed strong advancement and superiority, fits the need of current boost all-round quality education concept in our country, is the inevitable trend of future development. The superiority of the paperless examination includes: simplicity and high efficiency, flexibility and convenience, objectivity and scientific nature, fairness and impartiality, interesting and vivid, versatility and easy operation.

At present, the paperless examination has been popularized and applied in our country. The ministry of education examination center has clearly put forward in the work plan of "11th five-year", introduce high-tech way to traditional examination. Paperless examination is expected to change the education evaluation system as the core of examination in our country, change the current disadvantages of taking examination content to set education content and taking the examination condition to evaluate the education level, is the effective ways to realize open education which take the student as the center, has a positive effect to promote students' personalized learning and learning self-consciousness, it will be the trend of future development, but due to the automatic batch technology is not mature, the limitation of examination theory application, and the influence of examination environment, scale, and other factors, paperless examination still need to continuously explore in the road of development.

\section{References}

[1] Haihua Xiang. The review of database technology development[J]. Modern intelligence, 2003.

[2] Lili zhao, Yinbin Wang. Introduction to the development of the database system [J]. The development of science and technology intelligence and economy, 2005.

[3] Mingyi Liao, Hong Liu. The data warehouse and its application [J]. Journal of bohai university, 2005.6.

[4] Jiantao Qiao. Application status and prospects analysis of paperless examination[J]. Value engineering, 2011. 